\title{
CONDUCTING MEMBRANES AND COATINGS MADE FROM REDISPERSABLE NANOSCALED CRYSTALLINE $\mathrm{SnO}_{2}$ :Sb PARTICLES
}

\author{
C. GOEBBERT", M. A. AEGERTER*, D. BURGARD ${ }^{* *}$, R. NASS ${ }^{* *}$, H. SCHMIDT SH $^{* *}$ \\ Institut für Neue Materialien-INM, "Department of Coating Technology, "Department of \\ Chemistry and Technology of Nonmetallic-Inorganic Materials \\ D-66123 Saarbruecken, GERMANY
}

\section{ABSTRACT}

Inorganic membranes prepared by the sol gel method are promising candidates for use as filters in separation processes. Conducting supported membranes and coatings have been produced from redispersable nanoscaled crystalline $\mathrm{Sb}$-doped $\mathrm{SnO}_{2}$ powders with a $\mathrm{Sb}$ content up to 5 mole $\%$ (with respect to $\mathrm{Sn}$ ). The crystalline particles are monosized $(\cong 4 \mathrm{~nm}$ ) and fully redispersable in aqueous solution at $\mathrm{pH} \geq 8$ with a solid content up to $70 \mathrm{wt}$. $\%$. By thermal treatment at different temperatures and times, the pore size diameter of the material can be adjusted from 4 to $20 \mathrm{~nm}$ with a very narrow pore size distribution ( $\sim 1 \mathrm{~nm})$ and a total porosity of $63 \%$, practically independent of the sintering parameters. Uniaxial pressed substrates present similar characteristics with however larger pore size distribution $( \pm 5 \mathrm{~nm})$ and $80 \%$ total porosity. Their resistance decreases with sintering temperature and time down to $4 \Omega\left(800{ }^{\circ} \mathrm{C}\right.$, $8 \mathrm{~h}$ ). Fully dispersed aqueous solutions of the powder $(25 \mathrm{wt} \%)$ were used to prepare transparent conducting coatings on glass or ceramics by spin-coating. After thermal treatment (1 hour at $550^{\circ} \mathrm{C}$ ) single layers $200 \mathrm{~nm}$ thick exhibited a typical specific electrical resistance $\rho=2.5 \cdot 10^{-2} \Omega \mathrm{cm}$ with transmission in the visible range measured against air of $90 \%$.

\section{INTRODUCTION}

There is a growing interest for microbiological resistant and chemically stable materials in the development of membranes for separation processes. Polymeric materials deteriorate above $200^{\circ} \mathrm{C}$ or in the presence of organic solvents and do not always have the desired porous texture. Ceramic materials (such as alumina, silica, titania, zirconia, etc.) fulfil these requirements and are presently used in the preparation of membranes for microfiltration, ultrafiltration and hyperfiltration with pore sizes ranging between 100 to $1000 \mathrm{~nm}, 2$ to $100 \mathrm{~nm}$ and $<2 \mathrm{~nm}$ respectively [1].

The sol-gel process is a versatile technique for the preparation of ceramic membranes as it allows the control of the pore size and pore distribution [2]. The major problem lies in the obtention of thick coatings $(>1 \mu \mathrm{m})$ which may crack during the postsynthesis drying and sintering stages.

Sol-gel research in the field of micro- and ultrafiltration membranes has principally involved alumina $\left(\mathrm{Al}_{2} \mathrm{O}_{3}\right)$ and silica $\left(\mathrm{SiO}_{2}\right)$ materials [3-7] and transition metal oxides such as $\mathrm{TiO}_{2}$ and $\mathrm{ZrO}_{2}$ [7-9]. However, it has been recently shown that $\mathrm{SnO}_{2}$ has also appropriate microstructural characteristics for such applications [10-12]. The sols used for membrane preparation were aqueous colloidal suspensions (alkaline solution) containing spheroidal primary particles of $2 \mathrm{~nm}$ average size obtained from aqueous solution of tin chloride. Supported membranes have been realised using the sol-casting process on either micro or nanoporous $\alpha-\mathrm{Al}_{2} \mathrm{O}_{3}$ with subsequent 
drying at $110^{\circ} \mathrm{C}$ and firing at $400{ }^{\circ} \mathrm{C}$ for 2 hours $[11,12]$. Crack-free membranes were only found within a narrow concentration of $\mathrm{SnO}_{2}$ and electrolyte in the sol.

A novel and promising process for the obtention of oxide membranes for ultrafiltration and coatings is presented in this paper. The fabrication of advanced nanostructured membranes and ceramics requires high quality powders and their redispersability is a particulary important aspect. In a conventional synthesis, the intermediate particulate system minimizes its surface free energy by growing into larger particles which tend to agglomerate. These reactions can be avoided by adjusting the particles surface free energy by in-situ surface modification during the precipitation and the controlled growth processes so that unagglomerated particles with a determined size can be prepared. This process is outlined for $\mathrm{SnO}_{2}$ and electrical conducting $\mathrm{SnO}_{2}: \mathrm{Sb}$ materials, both being wide band semiconductors and $\mathrm{SnO}_{2}: \mathrm{Sb}$ a good electronic conductor presenting a specific resistivity as low as $1 \cdot 10^{-3} \Omega \mathrm{cm}$ [13]. The combination of conductivity or photocatalytic properties may be an asset for the developnent of membranes for hybrid processes. The paper describes the preparation and characterisation of redispersable, nanoscaled crystalline powder [14], unsupported membranes and thin and thick coatings made by the spin coated process.

\section{EXPERIMENTAL PROCEDURE}

\section{Powder and unsupported membrane preparation}

$\mathrm{SnO}_{2}$ and $\mathrm{SnO}_{2}: \mathrm{Sb}$ particles were prepared by a controlled growth technique [15-17]. A solution of tin(IV) chloride in ethanol containing up to 10 mole $\%$ of $\mathrm{SbCl}_{3}$ was added dropwise to an aqueous ammonia solution containing $10 \mathrm{wt} \%$, with respect to the oxide, of a surface modifying agent, $\beta$-alanine. The prepared suspensions were then treated in an autoclave at 150 ${ }^{\circ} \mathrm{C}$ and 10 bar for 3 hours. The resulting powder was isolated by centrifugation, washed with water several times and then dried at $60^{\circ} \mathrm{C}$. Such a powder is fully redispersable in water at $\mathrm{pH} \geq$ 8 under ultrasonic irradiation. The size of the particles was measured by Photon Correlation Spectroscopy (PCS) using a ALV-5000 equipment and High Resolution Transmission Microscopy (HRTEM). The analysis of the pore characteristics was performed by BET measurement (ASAP2400, Micromeritics) on loose powder thermally treated at different temperatures $\left(400\right.$ to $800{ }^{\circ} \mathrm{C}$ ) and times $(10,30,90,300 \mathrm{~min})$ and, in order to examine the stability and pore size characteristics of the powder as a membrane support, with broken round substrates $(1,8 \mathrm{~mm}$ thick and $38 \mathrm{~mm}$ in diameter) compacted in an uniaxial press $(100 \mathrm{kN})$. The discs were thermally treated at temperatures between 300 and $800{ }^{\circ} \mathrm{C}$ with sintering times of 0.5 , $1,4,8 \mathrm{~h}$. The powders and ceramic parts were also characterised by X-ray diffraction (XRD) and density measurement with a pycnometer (AccuPyc1330, Micromeritics). The electrical resistance of the membranes was measured by a 2 points technique across their thickness.

\section{Coating preparation}

Colloidal suspensions were prepared by dispersing the non-thermally treated powder in water at $\mathrm{pH} \geq 11 \mathrm{using} 0.78 \mathrm{~mole} / 1$ tetramethylammoniahydroxide (TMAH) as a base. After powder addition the resulting suspensions were submitted to ultrasound irradiation for 2 minutes. After this treatment the suspensions were stirred for one day. The final dispersions were clear with a yellowish orange colour. Stable suspensions can be obtained up to a solid content of 70 wt. $\%$. 
Conducting coatings on borofloat glass or alumina substrates have been prepared using the spin coating process. At a final speed of $2500 \mathrm{rpm}$ for 15 seconds crack-free spin coated coatings could be obtained with a solid content up to $25 \mathrm{wt}$. \%. The thermal densification of the film was carried out at temperatures from 400 to $600^{\circ} \mathrm{C}$ for 0.25 to $8 \mathrm{~h}$. The film thickness was measured with a Tencor P10 surface profiler. The characterisation of the electrical properties was carried out by the 4-point and van der Pauw/Hall technique (MMR Technologies) and the coating texture was analyzed by HRTEM and Atomic Force Microscopy (AFM).

\section{RESULTS AND DISCUSSION}

\section{Powder characterisation}

The structure of the dried $\mathrm{SnO}_{2}$ and $\mathrm{SnO}_{2}: \mathrm{Sb}$ powders is shown in Figure 1. The particles are already crystalline and have a cassiterite structure. The vertical lines drawn on the figure correspond to the data taken from the JCPDS for this structure. They are not orientated and have a crystallite size, calculated with a Siemens software for the (110) peak, ol $7 \mathrm{~nm}$ for $\mathrm{SnO}_{2}$ and 3 $\mathrm{nm}$ for $\mathrm{Sb}$ doped $\mathrm{SnO}_{2}$. A systematic decrease was observed with increasing antimony content.
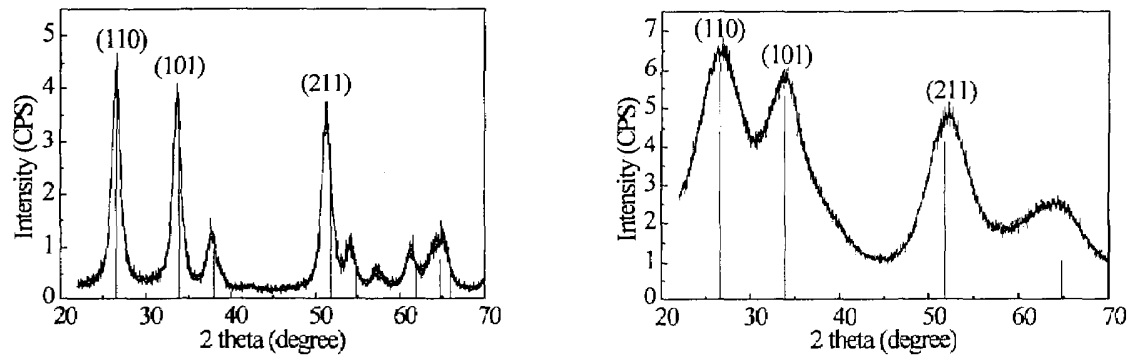

Figure 1: X-ray diffraction of dried nanoscaled, crystalline powder prepared by a controlled growth reaction at $150^{\circ} \mathrm{C}$ and 10 bar for 3 hours. Left: $\mathrm{SnO}_{2}$, right: $\mathrm{SnO}_{2}: \mathrm{Sb}(5$ mole \%)

The size of the particle was confirmed by PCS (figure 2) and HRTEM measurements (figure 3). The hydrodynamic size of the particles shows a shift from $4 \mathrm{~nm}$ to $2 \mathrm{~nm}$. This shift is only due to the reduction of the free volume of the solvent. At low particle concentrations, a ,gas like state" can be assumed, where no correlation of the motion of the particles can be found and the shear deformation rate is low compared with the self diffusion of the particles [18].

Figure 3 is a HRTEM picture of a droplet of a dried suspension showing crystalline particles with an average size of 3 to $5 \mathrm{~nm}$ with no evidence of aggregation. Each particle is probably formed by a single crystallite. 

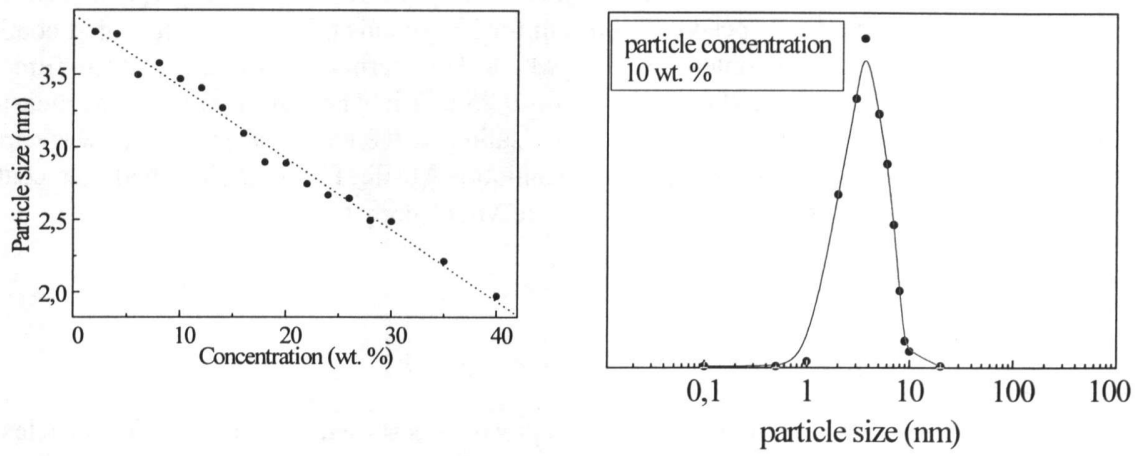

Figure 2: Left: Hydrodynamic Particle size in the suspension vs particle concentration measured by Photon Correlation Spectroscopy (PCS). Right: Particle size distribution.

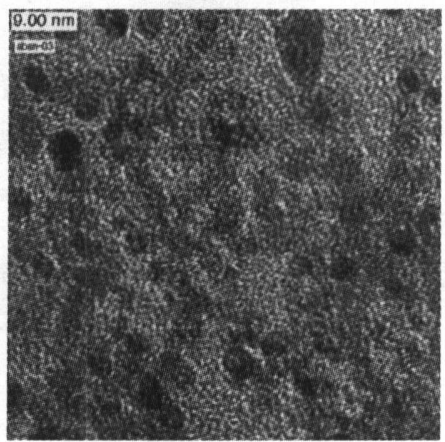

Figure 3: HRTEM picture of nanocrystalline $\mathrm{SnO}_{2}: \mathrm{Sb}$ powder obtained by a controlled growth reaction and hydrothermal crystallisation at $150{ }^{\circ} \mathrm{C}$ and 10 bar for 3 hours, redispersed in water and TMAH.

The evolution of the powder porosity after different heat treatment is shown in figure 4 where the $\mathrm{N}_{2}$ adsorption and desorption isotherms are compared. According to the IUPAC recommendation [19], the BET isotherms have a type IV shape at all temperatures. The hysteresis is of type $\mathrm{H}_{2}$ at low temperature and typical for capillary condensation inside inkbottle shaped mesopores of corpuscular systems. At high sintering temperatures the hysteresis tends towards a H1 type indicating a higher regularity of the cross section along the longitudinal direction of the pores (transformation of an ink-bottle shape towards a cylindrical shape [10]). 


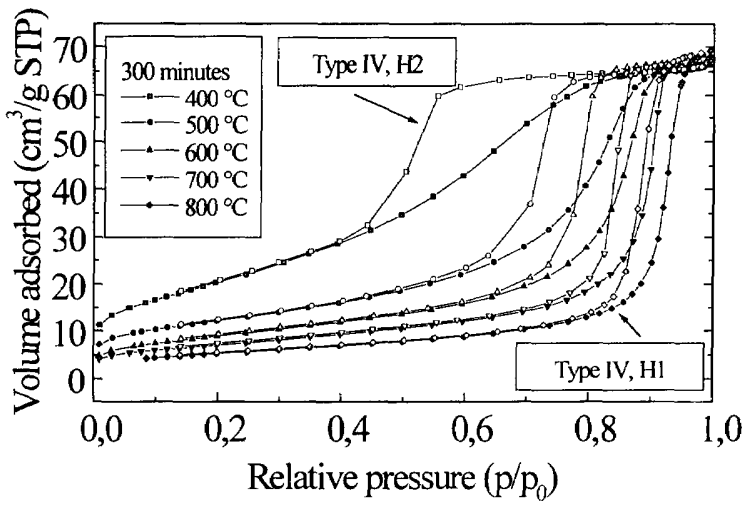

Figure 4: $\mathrm{N}_{2}$ adsorption and desorption isotherms of $\mathrm{SnO}_{2}: \mathrm{Sb}$ powder heat treated at different temperatures during $5 \mathrm{~h}$. (solid symbol = adsorption; open symbol $=$ desorption)

The pore size distribution curves were determined from the desorption branches. Figure 5 indicates a strong increase of the pore size with the temperature of the heat treatment. For 400 ${ }^{\circ} \mathrm{C}, 10 \mathrm{~min}$ or lower temperature the pore size distribution is large showing the presence of micropores. By increasing the sintering temperature, the pore size distribution become narrower, about $\pm 1 \mathrm{~nm}$, and the average diameter shifts from $4 \mathrm{~nm}\left(400^{\circ} \mathrm{C}\right)$ to $15-20 \mathrm{~nm}\left(800^{\circ} \mathrm{C}\right)$ while the maximum pore volume remains constant with a value of about $0.75 \mathrm{~cm}^{3} / \mathrm{g}$. A longer sintering time gives a better defined pore size distribution with a slight shift of their size. This overall behaviour of the evolution of the pore size distribution has been already observed with undoped $\mathrm{SnO}_{2}$ xerogel [10]. However, there are some interesting differences. For $\mathrm{SnO}_{2}: \mathrm{Sb}$ prepared by a controlled growth reaction, the pore volume is always higher than that of $\mathrm{SnO}_{2}$ xerogel especially for the distribution at $400{ }^{\circ} \mathrm{C}$ and for those at $\mathrm{T} \geq 700{ }^{\circ} \mathrm{C}$. At $700{ }^{\circ} \mathrm{C}$ the maximum pore volume of undoped $\mathrm{SnO}_{2}$ xerogel is already strongly reduced to about $0,15 \mathrm{~cm}^{3} / \mathrm{g}$ and at $800{ }^{\circ} \mathrm{C}$ is not measurable, while for $\mathrm{SnO}_{2}: \mathrm{Sb}$ the volume is still high at $0,75 \mathrm{~cm}^{3} / \mathrm{g}$. It is not yet clear if this behaviour is due to the antimony doping or to the different method of preparation of the materials. $\mathrm{SnO}_{2}: \mathrm{Sb}$ is therefore better indicated for the realisation of membranes, where the pore diameter can be continuously adjusted with the sintering temperature and time with a narrow distribution in the range of 4 to $20 \mathrm{~nm}$. The total porosity of the powder is $63 \%$, practically independent of the sintering conditions.

Figure 6 shows the influence of the sintering temperature and time on the BET surface area and true density of the $\mathrm{SnO}_{2}: \mathrm{Sb}$ powder.

The $60^{\circ} \mathrm{C}$ dried powder, which has been prepared in the autoclave at $150{ }^{\circ} \mathrm{C}$, has a BET surface area of $220 \mathrm{~m}^{2} / \mathrm{g}$ and a true density of $4 \mathrm{~g} / \mathrm{cm}^{3}$. With the increase of the temperature and the sintering time the surface area decreases and reaches a minimum for each temperature for sintering time longer than about 300 minutes. The large decrease of the BET surface area at 400 ${ }^{\circ} \mathrm{C}$ is partly due to the gradual removal of the organic compound from the surface of the particles and partly to the removal of the microporosity (Figure 5). 


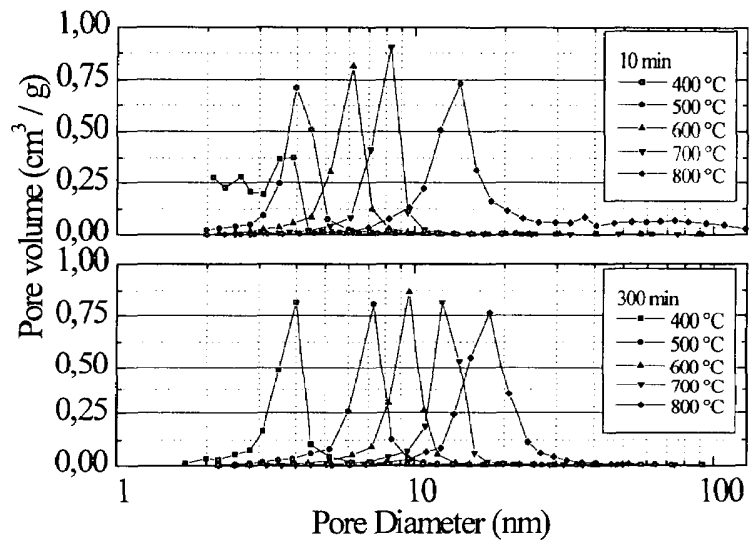

Figure 5: Evolution of pore characteristics (volume, size) of loose powder with sintering temperature and time.
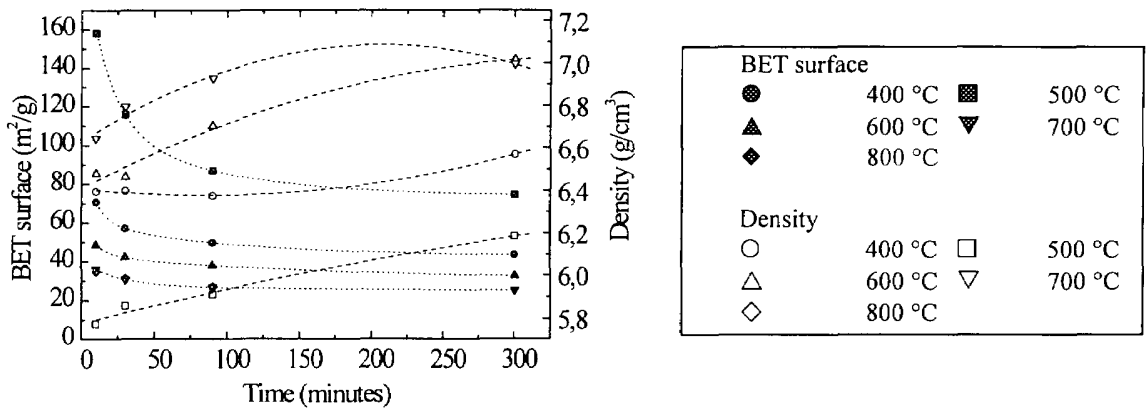

Figure 6: Influence of temperature and sintering time on the BET surface area and the true density of $\mathrm{SnO}_{2}: \mathrm{Sb}$ powder.

At higher temperature the reduction of the BET surface with the sintering time is smaller and in agreement with the change of the isotherm from type IV-H2 to type IV-H1 (better regularity). The true density increases in parallel with the sintering temperature and time and reaches at $700{ }^{\circ} \mathrm{C}(300 \mathrm{~min})$ or $800{ }^{\circ} \mathrm{C}(100 \mathrm{~min})$ values close to the theoretical density. The overal behaviour is in agreement with the results found by Santilli et al [20] for $\mathrm{SnO}_{2}$ xerogel, indicating that the sintering behaviour of $\mathrm{SnO}_{2}: \mathrm{Sb}$ obey a dynamic scaling model as for $\mathrm{SnO}_{2}$ and that this material can be seen as a two phases system composed by a nearly homogeneous $\mathrm{SnO}_{2}: \mathrm{Sb}$ matrix with high concentration of vacancy and empty microvoid. The total volume fraction of both phases (63\% for the porous phase, $37 \%$ for the solid phase) remains constant at least up to $800^{\circ} \mathrm{C}$ and the solid fraction reaches the theoretical value of the density at high temperatures $\left(800^{\circ} \mathrm{C}, 100 \mathrm{~min}\right)$. Under these conditions no significant bulk densification occurs 
in this temperature range, confirming the great interest of this material for the realisation of ultrafiltration membranes.

Without heat treatment the dried $\mathrm{SnO}_{2}: \mathrm{Sb}$ powder is already crystalline with a crystallite size of $\sim 4 \mathrm{~nm}$ as shown by X-ray diffraction, HRTEM and PCS measurements. By heating at $400{ }^{\circ} \mathrm{C}$ during $10 \mathrm{~min}$, the crystalline size is smaller $(\sim 2,5 \mathrm{~nm})$ (figure 7$)$. It is thought that this reduction is due to the elimination of the microporosity (figure 5). Another proof of it is the increase of the density from $4 \mathrm{~g} / \mathrm{cm}^{3}$ to $5.8 \mathrm{~g} / \mathrm{cm}^{3}$ (figure 6). The size of the crystallites then increase with temperature and time of sintering up to values of $20 \mathrm{~nm}\left(800{ }^{\circ} \mathrm{C}, 300 \mathrm{~min}\right)$. The particle size $G$ can be evaluated using specific surface and density data (equation 1) where $S_{\mathrm{BET}}$ is the surface area in $\mathrm{m}^{2} / \mathrm{g}, \rho$ the true density in $\mathrm{g} / \mathrm{cm}^{3}$ (both taken from figure 6) and $\mathrm{f}$ is a coefficient which depends on the shape and the distribution of the particles.

$$
G(n m)=f \cdot 10^{3}\left(S_{B E T}(T, t) \cdot \rho(T, t)\right)^{-1}
$$

Figure 7 shows also a plot of the function $\mathrm{G} / \mathrm{f}$ vs sintering time. The overall behaviour is identical to that of the crystallite size. Crystallites and particles appear therefore to grow following the same law. For sintering time $t \geq 30$ min the sizes grow as $D(t)=k \cdot t^{n}$ where $n$ is smaller than 1 , the value expected for the classical crystallite growth mechanism.

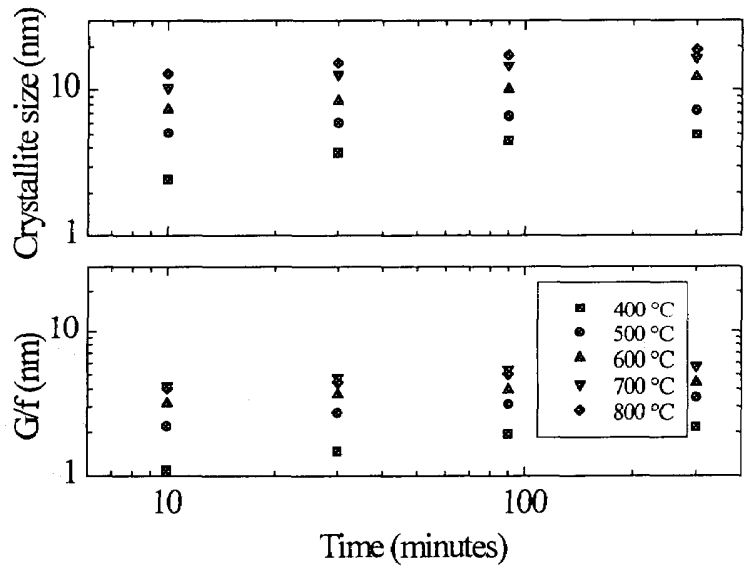

Figure 7: Influence of temperature and sintering time on the crystallite size obtained from Xray diffraction and plot of the function $\mathrm{G} / \mathrm{f}$ (see text) calculated from specific surface area and density measurement.

\section{Unsupported membranes}

The uniaxial pressed substrates show similar results. The $\mathrm{N}_{2}$ adsorption and desorption isotherms are shown in figure 8. The overall behaviour is similar to that presented for the loose powder shown in figure 4 . The isotherms are of type IV with $\mathrm{H} 2$ hysteresis transforming into $\mathrm{H} 1$ type at high temperatures $\left(800^{\circ} \mathrm{C}\right)$. The pore size also varied from 4 to $20 \mathrm{~nm}$ depending on the sintering time and temperature, but the distribution is larger $(\sim \pm 5 \mathrm{~nm})$ and the total porosity is 
higher $(80 \%)$. The true density increases and the BET surface area decreases in a similar way the loose powder did (figure 6). The electrical resistance of the pellets strongly decreases with increasing sintering temperature and time (figure 9).

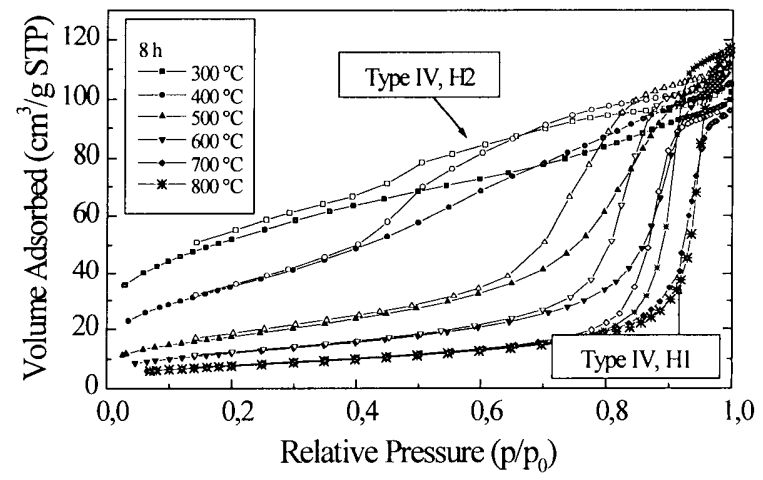

Figure 8: $\mathrm{N}_{2}$ adsorption and desorption isotherms of uniaxially pressed powder after sintering at different temperatures during $8 \mathrm{~h}$. (solid symbol = adsorntion; open symbol = desorption)

Dried pellets have a very high electrical resistance. With higher temperature and sintering time it decreases from $360 \mathrm{k} \Omega\left(300{ }^{\circ} \mathrm{C}, 30 \mathrm{~min}\right)$ to $4 \Omega$ for $700{ }^{\circ} \mathrm{C}, 8$ hours. These values are higher than those obtained with coatings (see below).

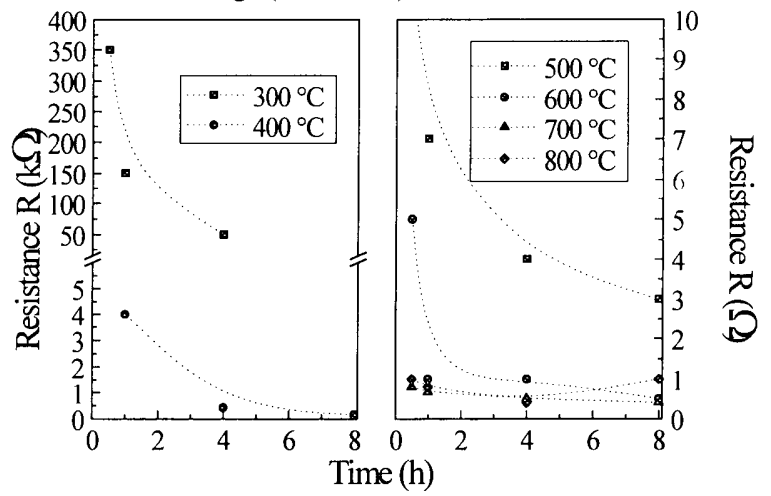

Figure 9: Change of the electrical resistance of pressed $\mathrm{SnO}_{2}: \mathrm{Sb}$ substrates versus sintering time for different sintering temperatures.

\section{$\underline{\text { Sol for coating }}$}

For the preparation of porous coatings using nanoscaled crystalline particles, the powder was redispersed in water. The stability of the dispersion was determined by measuring the $\xi$ potential and is strongly dependant on the $\mathrm{pH}$ of the solvent (Figure10). The isoelectrical point of the 
surface modified powder lies at a $\mathrm{pH}_{\text {iep }}$ of 3.7 . The suspension is stable at $\mathrm{pH}>8$ and no evidence for instability could be found with solid contents up to $40 \mathrm{wt} \%$.

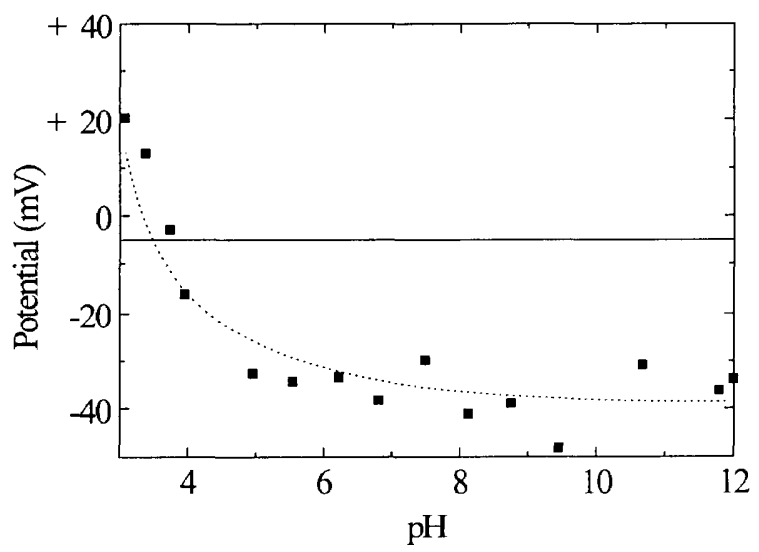

Figure 10: $\xi$ potential of the suspension vs $\mathrm{pH}$

With increasing particle concentration, the sol viscosity increases (figure 11) due to interactions among the particles but evidence for the formation of aggregates have not been found up to 40 wt. \%.

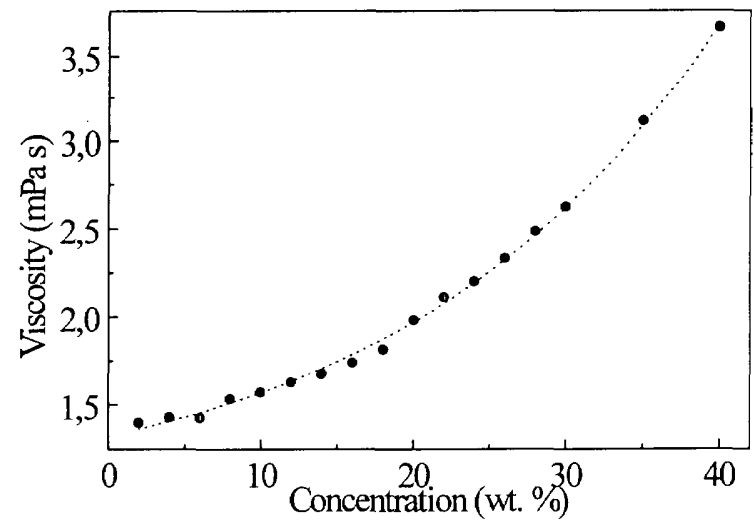

Figure 11: Viscosity of the sol with increasing particle concentration

\section{Film characterisation}

Films have been prepared on glass and alumina substrates using the spin coating technique. Each film was densified in a furnace immediately after the spin coating process. After firing, the films are uniform with a low roughness $\mathrm{R}<3 \mathrm{~nm}$ (see figure 14 right). The thickness of single 
layers increases with the particle concentration (figure 12) and this reflect the behaviour of the viscosity. Thickness as high as $500 \mathrm{~nm}$ can be obtained for a single layer. Thicker coatings can be prepared by repeating the coating and sintering process.

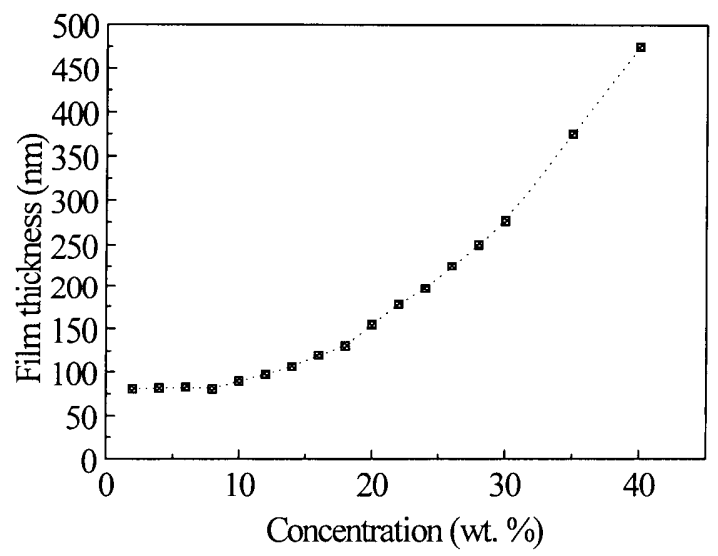

Figure 12: Thickness of spin coated single layers sintered at $550{ }^{\circ} \mathrm{C}$ during 15 minutes vs $\mathrm{SnO}_{2}: \mathrm{Sb}$ particle concentration of the sol.

The lowest resistivities are reached with a $25 \mathrm{wt}$. \% solid content of the powder in the sol. With higher concentration the films start to crack. With this concentration single layers have a thickness of $200 \mathrm{~nm}$ after firing. As for the pressed substrate, the electrical resistance of the films depends on the temperature and time of the sintering process. Figure 13 shows the resistivity of $200 \mathrm{~nm}$ thick single layers sintered at different temperatures and times. The lowest resistivity, $2.5 \cdot 10^{-2} \Omega \mathrm{cm}$, was obtained after sintering at $550^{\circ} \mathrm{C}$ during $1 \mathrm{~h}$. The coating has an electron mobility $\mu=1 \mathrm{~cm}^{2} / \mathrm{Vs}$ and an electron density $\mathrm{n}=2,15 \cdot 10^{20} \mathrm{~cm}^{-3}$. The transmission in the visible range is $85-90 \%$.

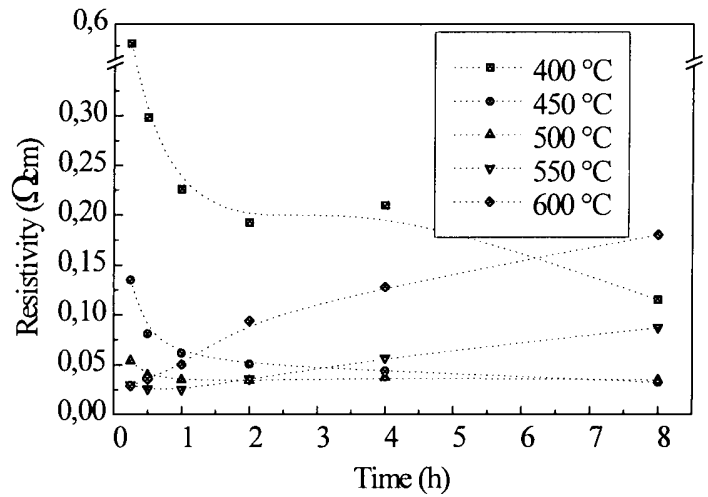

Figure 13: Resistivity vs sintering time for different sintering temperatures. Films were made with a $20 \mathrm{wt}$. \% particle concentration in the sol. 
A HRTEM cross-section of a multi-layer film is shown in figure 14. The film is made of porous and interconnected particles and a denser layer ( $20 \mathrm{~nm}$ thick) is observed on top of each layer. This layer has a higher conductivity than the bulk of the coating [21]. However, if each layer is dried at $150^{\circ} \mathrm{C}$ between each deposition and the multilayer coating sintered as a whole at higher temperature, these denser layers do not occur and the coating is homogeneous. The resistivity of the coatings is much lower than that of the pressed substrates. Although their structure is still porous the coatings have probably a smaller total porosity. Such measurements are underway. In figure 14 (right) an AFM picture is shown. The coating is smooth and shows no evidence of large cracks or peel-off from the glass substrate.
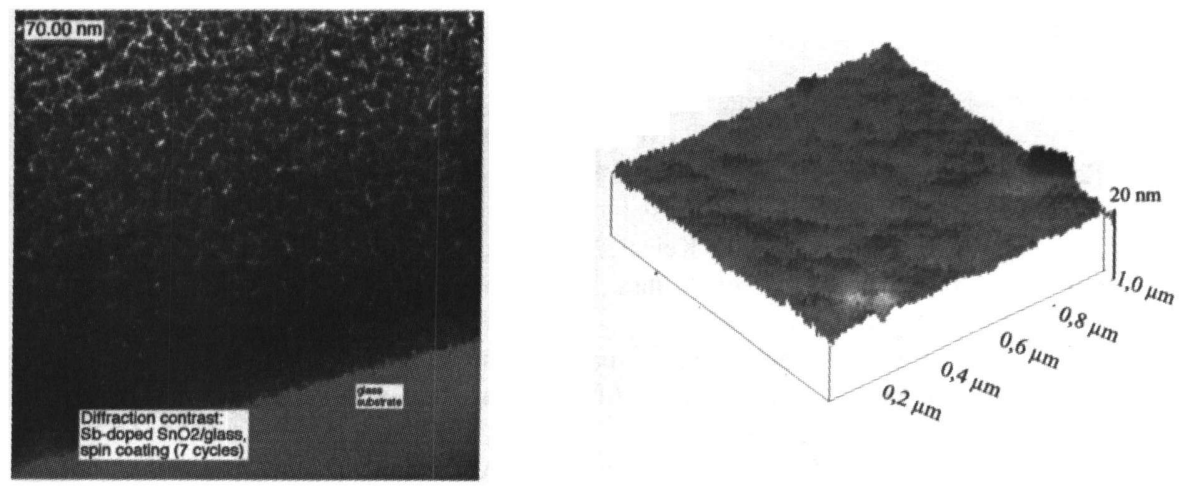

Figure 14 (left): Cross-section of a multi-layer $\mathrm{SnO}_{2}: \mathrm{Sb}$ coating deposited by spin coating on a glass substrate with a particulate sol having a solid content $25 \mathrm{wt}$. \%. Each layer was sintered in air at $550^{\circ} \mathrm{C}$ during $15 \mathrm{~min}$ (each layer)

Figure 14 (right): Atomic Force Microscopy (AFM) of a single layer deposited by spin coating on a glass substrate with a particulate sol having a solid content $25 \mathrm{wt}$. \%, sintered in air at $550^{\circ} \mathrm{C}$ during $15 \mathrm{~min}$.

\section{CONCLUSION}

Nanoscaled, crystalline $\mathrm{SnO}_{2}$ and $\mathrm{SnO}_{2}: \mathrm{Sb}$ particles fully redispersable in water have been prepared. The growth of the particles in a solution was controlled by chemical modification of the particle surface using $\beta$-alanine. Dried powders can be fully redispersed in water at a nanoscaled level. Suspension with solid content up to 70 weight $\%$ are stable for $\mathrm{pH}>8$. Thick coating (up to $0.5 \mu \mathrm{m} /$ layer) have been obtained by spin coating process. The specific resistivity of $\mathrm{SnO}_{2}: \mathrm{Sb}$ coatings depends on the thickness, the particle concentration, temperature and time of the sintering process. Resistivity values as low as $\rho=2,5 \cdot 10^{-2} \Omega \mathrm{cm}$ with sheet resistance of $R_{\square}$ $=60 \Omega_{\square}$ has been obtained for 7- layer coating (thickness $1,4 \mu \mathrm{m}$ ). Loose powders heat treated in air exhibit microporosity with narrow pore size distribution $( \pm 1 \mathrm{~nm})$. The pore size can be continuously varied in a controlled way between $4 \mathrm{~nm}\left(400^{\circ} \mathrm{C}\right)$ to $20 \mathrm{~nm}\left(800^{\circ} \mathrm{C}\right)$. Uniaxial pressed unsupported membranes show similar characteristics. The pore size distribution is 
however higher $( \pm 5 \mathrm{~nm})$ ant the total porosity is $80 \%$. The electrical resistance of these membranes typically varies from $360 \mathrm{k} \Omega\left(400^{\circ} \mathrm{C}\right)$ to $4 \Omega\left(800^{\circ} \mathrm{C}\right)$. These materials offer high chemical and thermal resistance and is therefore promising for industrial preparation of conducting membranes for ultrafiltration and transparent conducting layer for antistatic application or for systems which need sheet resistance larger than about $100 \Omega_{\square}$ such as touch screen panels.

\section{ACKNOWLEDGEMENT}

Research supported by BMBF (2 A 67/03 N 9040) and the state of Saarland (Germany)

\section{REFERENCES}

[1] R. R. Bhave, Inorganic Membranes: Synthesis, Characteristics and Application, Van Nostrand Reinhold, New york 1991.

[2] C. J. Brinker, G. W. Scherer, Sol-Gel Science: The physics and chemistry of solgel processing, Acad. Press Inc., San Diego, USA 1990.

[3] A. F. M. Leenaars, K. Keizer, A. J. Burggraaf, J. Mat. Sci. 19 (1984), 1077.

[4] A. Larbot, S. Alami-Younssi, M. Persin, J. Sarrazin, L. Cot, J. Membr. Sci. 97 (1994), 167.

[5] M. I. D. d. Albani, C. P. Arciprete, J. Membr. Sci. 69 (1992), 21.

[6] C. J. Brinker, N. K. Raman, M. N. Logan, R. Sehgal, R. A. Assink, D. W. Hua, T.

L. Ward, J. Sol-Gel Sci. Tech. 4 (1995), 117.

[7] L. C. Klein, C. Yu, R. Woodman, R. PAvlik, Catal. Today 14 (1992), 165.

[8] A. Larbot, J. P. Fabre, L. Cot, J. Amer. Ceram. Soc. 72 (1989), 257.

[9] C. Guizard, A. Julbe, A. Larbot, L. Cot, J. Alloys Comp. 8 (1992), 188.

[10] G. E. S. Brito, S. H. Pulcinelli, C. V. Santilli, J. Sol-Gel Sci. Tech. 2 (1994), 575.

[11] L. R. B. Santos, S. H. Pulcinelli, C. V. Santilli, J. Sol-Gel Sci. Tech. 8 (1997), .

[12] L. R. B. Santos, S. H. Pulcinelli, C. V. Santilli, J. Memb. Sci. 127 (1997), 77-86.

[13] G. Gasparro, J. Pütz, D. Ganz, M. A. Aegerter, EuroSun'96 International Symposium on Optical Materials Technology for Energy Efficiency and Solar Energy Conversion (Freiburg), Parameters Affecting the Electrical Conductivity of $\mathrm{SnO}_{2}: \mathrm{Sb}$ Sol-Gel Coatings (1996).

[14] D. Burgard, C. Goebbert, R. Nass, J. Sol-Gel Sci. Tech. (in press), .

[15] D. Burgard, R. Nass, H. Schmidt, , Aqueous Chemistry and Geochemistry of Oxides, Oxyhydroxides and related Materials, MRS 432, pp. 113-20 (1997).

[16] D. Burgard, R. Nass, H. Schmidt, Werkstoffwoche, Symp. 6 Werkstoff und Verfahrenstechnik, pp. 569-77 (1997).

[17] D. Burgard, C. Kropf, R. Nass, H. Schmidt in Better Ceramics through Chemistry, MRS 346 pp. 101-7 (1994).

[18] J. Persello, A. Magnin, J. Chang, J. M. Piau, B. Cabane, J. Rheol. 38 (1994), 1845.

[19] IUPAC, Pure Appl. Chem. 57 (1985), 603.

[20] C. V. Santilli, S. H. Pulcinelli, D. F. Craierich, Phys. Rev. B 51 (1995), 8801-9.

[21] J. Pütz, D. Ganz, G. Gasparro, M. A. Aegerter, Proc. Int. Conference Sol-Gel 97, 31.08-05.09.1997, Sheffield, UK (1997), . 